\title{
O IMPACTO DAS MARCAS IFRN E INCUBADORA ITNC NO DESENVOLVIMENTO DE STARTUPS
}

\section{THE IMPACT OF THE IFRN AND INCUADORA ITNC BRANDS ON THE DEVELOPMENT OF STARTUPS}

\section{EL IMPACTO DE LAS MARCAS IFRN E INCUADORA ITNC EN EL DESARROLLO DE STARTUPS}

\author{
Amanda Mitchell de Morais Pereira ${ }^{1}$ \\ Marli de Fátima Ferraz da Silva Tacconi ${ }^{2}$ \\ Ernesto Alexandre Tacconi Neto ${ }^{3}$
}

Artigo recebido em janeiro de 2021

Artigo aceito em novembro de 2021

\begin{abstract}
RESUMO
As empresas se estabelecem como essenciais para o desenvolvimento econômico. Por isso, é importante apoiar essas instituições, principalmente as de pequeno porte, que tendem a apresentar mais dificuldades em se tornarem competitivas. As incubadoras tecnológicas se mostram mecanismo eficiente que conecta micro e pequenas empresas às instituições educacionais, facilitando o acesso a conhecimentos tecnológicos e a cooperação. Um dos elementos da incubadora universitária, potencialmente valorizador das startups é a associação a marca corporativa como importante extensão de influência, indo, além disso, e servindo como selo de garantia de qualidade técnica. O objetivo da investigação se centra em analisar a percepção das startups sobre o impacto das marcas do IFRN (Instituto Federal de educação, Ciência e Tecnologia do Rio Grande do Norte) e da ITNC (Incubadora Tecnológica Natal Central) no desenvolvimento dos seus negócios. A metodologia se concentrou em estudo exploratório e descritivo, com abordagem qualitativa e quantitativa. Coletaram-se os dados por meio de questionário e roteiro semiestruturado, atingindo 13 empresas incubadas. Trataram-se os dados por meio da Análise de Conteúdo e da Análise Descritiva. Os resultados revelaram que a estrutura ofertada e as marcas do IFRN e do ITNC se configuraram os aspectos mais importantes como motivadores à escolha da incubação. O grau de satisfação das empresas incubadas com a ITNC foi alto e a marca IFRN foi a mais bem avaliada.
\end{abstract}

Palavras-chave: Incubadora Tecnológica. Startups. Gestão de Marcas. Marca.

\begin{abstract}
Companies establish themselves as essential for economic development. Therefore, it is important to support these institutions, especially the small ones, which tend to have more difficulties in becoming competitive. Technological incubators are an efficient mechanism that connects micro and small companies to educational institutions, facilitating access to technological knowledge and cooperation. One of the elements of the university incubator, potentially enhancing startups, is the association with the corporate brand as an important

\footnotetext{
1 Discente em Administração de Negócios Internacionais na Hochschule Rhein-Waal. E-mail: amitchellm4s@gmail.com.

${ }^{2}$ Professora no IFRN. E-mail: marli.tacconi@ifrn.edu.br.

${ }^{3}$ Professor no IFRN. E-mail: ernesto.tacconi@ifrn.edu.br,
}

Refas - ISSN 2359-182X v.8, n.3

Fevereiro de 2022 
extension of influence, going beyond that and serving as a seal of technical quality assurance. The objective of the investigation focuses on analyzing the perception of startups about the impact of the IFRN (Federal Institute of Education, Science and Technology of Rio Grande do Norte) and ITNC (Natal Central Technological Incubator) brands on the development of their businesses. The methodology focused on an exploratory and descriptive study, with a qualitative and quantitative approach. Data were collected through a questionnaire and semistructured script, reaching 13 incubated companies. Data were treated through Content Analysis and Descriptive Analysis. The results revealed that the structure offered and the IFRN and ITNC brands were the most important aspects as motivators for the choice of incubation. The degree of satisfaction of the companies incubated with ITNC was high and the IFRN brand was the best evaluated.

Keywords: Technological Incubator. Startups. Brand management. Brand.

\section{RESUMEN}

Las empresas se consolidan como esenciales para el desarrollo económico. Por lo tanto, es importante apoyar a estas instituciones, especialmente a las pequeñas, que suelen tener más dificultades para ser competitivas. Las incubadoras tecnológicas son un mecanismo eficiente que conecta a las micro y pequeñas empresas con las instituciones educativas, facilitando el acceso al conocimiento tecnológico y la cooperación. Uno de los elementos de la incubadora universitaria, potencialmente potenciadora de las startups, es la asociación con la marca corporativa como importante extensión de influencia, yendo más allá y sirviendo como sello de garantía de calidad técnica. El objetivo de la investigación se centra en analizar la percepción de las startups sobre el impacto de las marcas IFRN (Instituto Federal de Educación, Ciencia y Tecnología de Rio Grande do Norte) e ITNC (Incubadora Tecnológica Central Natal) en el desarrollo de sus negocios. La metodología se centró en un estudio exploratorio y descriptivo, con un enfoque cualitativo y cuantitativo. Los datos fueron recolectados a través de cuestionario y guión semiestructurado, llegando a 13 empresas incubadas. Los datos fueron tratados mediante Análisis de Contenido y Análisis Descriptivo. Los resultados revelaron que la estructura ofrecida y las marcas IFRN e ITNC fueron los aspectos más importantes como motivadores para la elección de la incubadora. El grado de satisfacción de las empresas incubadas con ITNC fue alto y la marca IFRN fue la mejor evaluada.

Palabras clave: Incubadora Tecnológica. Inauguración. Gestión de la marca. Marca.

\section{INTRODUÇÃO}

As empresas são essenciais para o desenvolvimento econômico, especialmente porque formam a raiz do processo dinâmico das inovações (ENGEL, 2018). Por isso, é importante apoiar essas instituições, principalmente as de pequeno porte, que tendem a apresentar mais dificuldades em se tornarem competitivas.

As incubadoras tecnológicas têm se mostrado mecanismo eficiente que conecta micro e pequenas empresas às instituições educacionais, facilitando acesso a conhecimentos tecnológicos e a cooperação. Essa cooperação proporciona auxílio na sobrevivência das empresas no mercado (MCTIC, 2018). 
Um dos elementos da incubadora universitária, potencialmente valorizador das startups é a associação a marca corporativa como importante extensão de influência, indo além e servindo como selo de garantia de qualidade técnica. Dessa forma, a marca da incubadora e, consequentemente, da instituição de ensino a que ela está vinculada, podem operar como um desbloqueio ao desconhecido, por meio da criação de associações positivas para as startups e ajudá-las a se destacar dos demais negócios (LACERDA, 2012). Contudo, a mesma autora ressalta que a literatura sobre incubadoras de startups não tem contemplado pesquisas sobre o branding como um dos benefícios trazidos pela integração das empresas a esses ambientes de incubação ou em parques tecnológicos.

Um ativo valioso por estar associado aos sentimentos dos consumidores, usuários e clientes em relação à marca e suas conexões é o branding. Para Kotler e Armstrong (2015), essa relação, sendo positiva, proporciona credibilidade e construção de relações de mercado mais sólidas e lucrativas. Credibilidade e network podem vir a ser uma base sólida para potencializar o sucesso de empresas recém-criadas.

Questões sobre "credibilidade" emergiram na pesquisa de Pereira (2016), na qual aparece como conceito essencial para a definição de uma estratégia de oferta das startups, quer seja para definições de produtos ou serviços, quer seja para a comunicação e distribuição. Dessa forma, a maioria das startups incubada verificou a necessidade de se aliar as entidades ou personagens que fossem identificadas como formadoras de opinião dentro da área comercial na qual atuam.

Nessa perspectiva, através deste estudo, os empreendedores podem compreender melhor como devem se posicionar em relação à marca do instituto e da incubadora e as instituições que apoiam esses empreendimentos podem ter uma visão mais clara sobre o impacto das suas marcas atreladas a esses negócios.

Nesse contexto, a questão da pesquisa é: qual o impacto das marcas da instituição de ensino e da incubadora para o desenvolvimento das startups?

Para este estudo, a instituição de ensino é o IFRN Campus Natal Central através da Diretoria de Pesquisa e Inovação (DIPEQ/CNAT), que efetiva suas políticas públicas de inovação por meio do Programa de Multincubação, e a incubadora é a ITNC que é a Incubadora Tecnológica Natal Central, com a visão de contribuir para a inovação tecnológica de produtos e/ou serviços em prol da economia local e o fomento do empreendedorismo.

O objetivo geral deste estudo é analisar a percepção das startups sobre o impacto das marcas do IFRN e da ITNC no desenvolvimento dos seus negócios. Para isso, foi necessário: verificar a importância e a satisfação em relação às marcas do instituto e da incubadora como apoiadoras das empresas incubadas; examinar os valores e associações percebidos em relação ao vínculo com a incubadora e a instituição de ensino; compreender o significado do vínculo as marcas da incubadora e da instituição de ensino para as incubadas e para o mercado.

\section{REFERENCIAL TEÓRICO}

Kotler e Armstrong (2015, p.4) definem o marketing como "processo administrativo e social pelo qual indivíduos e organizações obtêm o que necessitam e desejam por meio da criação e troca de valor". Então, o marketing pode ser entendido como um processo que 
constrói relacionamentos vantajosos seja com o intuito de comercializar um produto/serviço ou para apresentar uma ideia.

Após a revolução industrial, com a produção em grande escala de produtos, o marketing se preocupava apenas em fazer vendas, pensando em produtos com valores minimamente funcionais. Com o surgimento das tecnologias de informação, consumidores e clientes passaram a ter mais acesso a informações, comparando produtos com mais facilidade e efetuando compras com mais rapidez e praticidade. O marketing teve que encontrar meios de diferenciar produtos de seus concorrentes idênticos ou similares, escolhendo atributos de foco (posicionamento) e segmentando seu mercado (foco de esforços, investimentos e comunicação em um público com perfil mais específico), trabalhando com as emoções do público, levando em conta suas expectativas em busca da fidelização (KOTLER; KARTAJAYA; SETIAWAN, 2010).

Os profissionais de marketing vêm desempenhado um papel essencial para as organizações, uma vez que se habilitam a identificar e avaliar ideias, assim como interagir com as outras áreas organizacionais na busca do desenvolvimento adequado desses novos bens ou serviços para que seja efetivamente aceito no mercado. Essas ideias e interações podem variar desde a melhoria ou revisão de produtos existentes até a criação de um novo mercado (KOTLER; KELLER, 2012).

O desenvolvimento de novos produtos e serviços é uma das atividades básicas das empresas emergentes ou startups. As startups são empresas que apresentam capacidade de crescer em alta escala com base em ideias inovadoras e originais. As principais características dessas organizações são: "ser uma empresa inovadora e com identidade original; ser uma empresa escalável já que trabalha em velocidade rápida; investir no planejamento e consequentemente tem a burocracia reduzida e uma equipe com a identidade da empresa" (RISCHIONI; et al., 2020, p.22).

O desenvolvimento de novos produtos é sempre uma atividade que envolve riscos e que precisa ser centrada no cliente, com foco em descobrir novas formas de solucionar os problemas do consumidor e criar experiências satisfatórias (KOTLER; ARMSTRONG, 2015).

Inovações podem ser arriscadas e onerosas devido às inúmeras dificuldades que enfrentam, com grandes probabilidades de não serem bem sucedidas. Existe uma estimativa de que " $67 \%$ de todos os produtos lançados por empresas estabelecidas não dão certo. Para novas empresas, o índice de fracasso sobe para 90\%" (KOTLER; ARMSTRONG, 2015, p. 286). Esse processo complexo e arriscado é a alma dos negócios das startups, por isso, as incubadoras tecnológicas e as instituições de ensino são essenciais para minimizar os riscos e melhorar a eficácia desses novos negócios.

O Quadro 1 explora as características do marketing com foco nos novos empreendimentos e apresenta que as tendências holísticas da administração estratégica também se aplicam a um marketing voltado para o empreendedorismo.

O Quadro 1 descreve o quanto o marketing para essas empresas é diferenciado das empresas já estabelecidas no mercado. Portanto, um bom trabalho conjunto de marketing é imprescindível para reduzir os índices de fracasso nas startups. Essa parceria de marketing ofertada pelas incubadoras e pelas instituições de ensino, apoiadoras desses mecanismos, é oferecida as empresas incubadas. A prática de marketing dependerá sempre da tecnologia, do mercado no qual se esteja inserido e dos indivíduos envolvidos em todo o processo (PEREIRA, 2016). 
Conforme Kotler e Keller (2012), no processo de adoção de um novo produto o consumidor passa por um processo de "experienciação", podendo adotá-lo ou rejeitá-lo. Este procedimento é influenciado por vários fatores, sendo alguns de controle do profissional de marketing e outros não. Nesse sentido, dentre os aspectos que podem ser influenciados pelo marketing, o branding é uma questão que merece destaque.

Branding, que pode ser traduzido para "gestão de marcas", consiste nas atividades do marketing que atribuem e gerem o poder de marca a um produto, com o intuito de diferenciar este de seus concorrentes. O produto do marketing pode ser um bem, serviço, lugar ou organização (KOTLER, KELLER, 2012; TYBOUT, CALKINS, 2018; KOTLER, ARMSTRONG, 2015), podendo ser qualquer coisa com capacidade de adquirir associações.

Uma marca inspira confiança, pois carrega em sua essência um nível de qualidade percebida, podendo facilitar a escolha por um novo produto. Ela identifica a origem atribuindo responsabilidade de desempenho, seja ela boa ou ruim, com base em conceitos formados e compartilhados com e entre clientes, usuários e consumidores que já tenham tido alguma experiência com a marca, direta ou indiretamente. Mesmo que concorrentes possam copiar processos, desempenho e design, obstáculos surgem quando comparados com as impressões já formadas do mercado. Dessa forma, a marca vira um fator de vantagem competitiva para a empresa (KOTLER; KELLER, 2012).

Quadro 1 - Características do marketing em startups

\begin{tabular}{|c|c|}
\hline Características & Descrição \\
\hline $\begin{array}{l}\text { Informalidade } \\
\text { inerente da } \\
\text { estrutura, } \\
\text { evolução e } \\
\text { implementação }\end{array}$ & $\begin{array}{l}\text { Para as startups, o planejamento de marketing é informal na } \\
\text { estrutura, evolução e implementação. Há pouca ou nenhuma estrutura } \\
\text { e ferramentas formais. O marketing é realizado de acordo com as } \\
\text { capacidades e circunstâncias da pequena empresa. }\end{array}$ \\
\hline $\begin{array}{l}\text { Restrito na esfera } \\
\text { de atividade }\end{array}$ & $\begin{array}{l}\text { Devido aos seus recursos limitados, a atividade de marketing nas } \\
\text { pequenas empresas é inevitavelmente limitada no seu alcance e } \\
\text { intensidade. As startups não têm necessidade nem vontade de aplicar } \\
\text { estratégias de marketing e planos de alto custo. }\end{array}$ \\
\hline $\begin{array}{l}\text { Simplista e } \\
\text { aleatória / } \\
\text { ocasional }\end{array}$ & $\begin{array}{l}\text { A limitação de recursos nota-se no marketing, que é simplista, casual } \\
\text { e muitas vezes sensível e reativo à atividade dos concorrentes. }\end{array}$ \\
\hline Produtos & $\begin{array}{l}\text { As pequenas empresas, particularmente nos estágios iniciais de } \\
\text { desenvolvimento, são inerentemente orientadas para o produto, pelo } \\
\text { que não é nenhuma surpresa que uma grande parte do marketing seja } \\
\text { orientado para produtos, em comparação com os grandes } \\
\text { concorrentes. }\end{array}$ \\
\hline $\begin{array}{l}\text { Envolvimento } \\
\text { fundador } \\
\text { empreendedor }\end{array}$ & $\begin{array}{l}\text { A onipresença do fundador-empreendedor é talvez o fator mais } \\
\text { importante para o estilo de marketing das pequenas empresas. A } \\
\text { pessoa responsável está envolvida em todos os aspetos do negócio e o } \\
\text { marketing não é exceção. O empresário deve estar comprometido } \\
\text { com o marketing. }\end{array}$ \\
\hline
\end{tabular}

Fonte: Adaptado de Franco et al. (2014) apud Pereira (2016, p. 16) 
A marca é uma entidade perceptiva, com origem na realidade apesar de refletir os conceitos formados por terceiros. Essas impressões são moldadas pelo valor percebido, que é o resultado da avaliação entre benefícios, custos e alternativas. Um valor superior pode ser acrescentado por meio de benefícios funcionais, emocionais ou pela redução de custos que influenciam o preço final do produto (KOTLER, KELLER, 2012; TYBOUT, CALKINS, 2018).

O valor da marca é muitas vezes denominado de brand equity. Para Kotler e Keller (2012) o brand equity pode ser impulsionado de três formas: por elementos ou identidade da marca, como nome, logomarca, símbolos, propagandas, embalagem, entre outros; por um produto específico da marca e todas as atividades de marketing associadas a ele, seja desempenho e/ou relacionamento dos produtos da marca com o público; e por associações indiretas derivadas do uso de influenciadores ou referências.

Umas das fontes de associações indiretas podem ser outras marcas. Esta estratégia de associação é denominada co-branding, na qual as marcas colaboram entre si, fazendo uso do brand equity da outra ou executando atividades em parceria para agregar valor simultaneamente às duas marcas.

O co-branding não produz apenas uma integralidade de valores como igualmente pode fornecer vantagens complementares. A marca parceira pode atingir um público que a outra não tem contato, podendo ser de categorias diferentes ou não. Todavia, é importante lembrar que o co-branding, quando planejado, tem limitações contratuais, licenças jurídicas e riscos de imagem. Essa parceria deve ser gerenciada com cautela e de forma sinérgica para que não ocorram erros que possam prejudicar as duas marcas (KOTLER; ARMSTRONG, 2015).

De acordo com Tybout e Calkins (2018), o valor de uma marca pode ser medido por: métricas de marca baseada no cliente, referentes a atitudes, opiniões e crenças dos consumidores para compreender o relacionamento deles com a marca; pelas vendas incrementais da marca, provindas do desempenho e retorno de produtos relacionados; e/ou pelo valor da marca para a empresa, no qual se analisa o valor financeiro da marca, considerando-a um ativo da empresa.

Um caminho pertinente de mensuração para marcas com finalidades públicas, devido a sua natureza e objetivo, é o de métricas baseadas no cliente, que visa analisar a reputação da marca. Nessa direção, Tybout e Calkins (2018) sugerem o modelo BrandDynamics. A metodologia desse modelo se define pela abordagem de cinco perguntas que definem cinco níveis hierárquicos de relacionamento com a marca: (1) Ligação: "nenhuma outra é melhor que ela?"; (2) Vantagem: "ela me oferece algo melhor que as outras?"; (3) Desempenho: "ela pode entregar o que promete?”; (4) Relevância: "ela me oferece algo?”; (5) Presença: eu a conheço?

Esse método também deve ser aplicado de forma contínua para a tomada de decisões em relação à marca, porque é essencial saber as mudanças nas atitudes, opiniões e crenças para verificar de forma efetiva o valor da marca em comparação ao tempo de existência, onde ela está melhorando e/ou piorando e tomar as decisões necessárias.

Aliado a tudo isso, as marcas são ativos poderosos que devem ser desenvolvidos e gerenciados de forma cuidadosa, porque são muito mais do que símbolos ou nomes, e sim elementos-chave no relacionamento entre organizações e clientes (KOTLER; ARMSTRONG, 2015). Dessa forma, as marcas podem influenciar escolhas e gerar confiança para receitas 
futuras (KOTLER; KELLER, 2012). Isso torna a marca uma ferramenta de negociação e influência quando há uma conscientização sobre seu poder.

Shih e Aaboen (2019), ao analisarem a influência da mediação de incubadoras, identificaram que a associação do nome da marca com a incubadora e com as relações que ela possui, geram um impacto positivo no processo de networking das empresas incubadas no mercado.

Pode-se dizer então que o branding cria e gerencia conceitos e, consequentemente, a imagem de uma marca, definindo sua origem e essência, elaborando uma oportunidade para stakeholders de avaliar um produto ou serviço de forma diferente apenas com a forma com que ela se destaca ou se apresenta no mercado. "À medida que a vida das pessoas se torna mais complexa, agitada e corrida, a capacidade que as marcas têm de simplificar a tomada de decisões e reduzir riscos se torna inestimável” (KOTLER; KELLER, 2012, p. 258).

Dessa forma, uma marca é identificada com base em experiências anteriores que avaliam se o uso ou consumo de um produto/serviço derivado dela atendeu às necessidades e os desejos ou não. Portanto, positivos ou negativos, os efeitos dessas experiências com a marca são penetrantes na mente das pessoas. Logo, é possível entender que há possíveis benefícios oriundos do trabalho conjunto de uma incubadora junto às empresas a ela relacionadas. Para Lacerda (2012), a ligação do branding da incubadora e da instituição na qual a incubadora está atrelada, possibilita a transferência de associações positivas para as empresas, gerando valor para os seus negócios.

\section{MÉTODO}

Esta é uma pesquisa aplicada, envolvendo verdades e interesses locais a fim de produzir conhecimento prático para solução de problemas específicos (SILVA; MENEZES, 2001). Com um objetivo exploratório-descritivo, este estudo teve a intenção de descrever as características de uma população ou fenômeno específico. A pesquisa é exploratória pelo fato de proporcionar uma abordagem mais ampla sobre o fenômeno para que se tenha uma compreensão mais abrangente do mesmo (GIL, 1987).

Foi utilizada uma abordagem qualitativa e quantitativa. A abordagem qualitativa permite uma ampla gama de respostas possíveis com métodos de mensuração relativamente não estruturados (KOTLER; KELLER, 2012). Conforme Fachin (2017), a variável qualitativa é marcada por seus atributos e relaciona aspectos não somente mensuráveis, mas incluem aspectos definidos descritivamente. Já a abordagem quantitativa, para Silva e Menezes (2001), significa traduzir em números as opiniões e informações para classificá-las e analisálas, requerendo o uso de recursos e técnicas estatísticas.

Os instrumentos utilizados para a coleta dos dados foram compostos por roteiros semiestruturados, para um desenvolvimento de entrevistas em profundidade. $\mathrm{O}$ primeiro instrumento, o questionário, foi quantitativo a fim de avaliar o grau de importância e satisfação de alguns elementos. Já a segunda parte do instrumento foi composto por um roteiro de cunho qualitativo a fim de identificar percepções e associações dos conceitos em análise.

Para esses roteiros, os questionamentos foram adaptados do trabalho de Mestrado em Marketing de Lacerda (2012). 
O campo de aplicação do instrumento de pesquisa se restringiu a Incubadora Tecnológica do Natal Central - ITNC e ao Instituto Federal de Educação Ciência e Tecnologia do Rio Grande do Norte - IFRN. Essa incubadora possui a certificação nível 2 do Projeto do Centro de Referência para Apoio a Novos Empreendimentos - CERNE. Os sujeitos de pesquisa foram formados pelas treze empresas incubadas na ITNC, que é sua capacidade total. Foi possível aplicar os questionários junto às todas as empresas, contudo, na parte qualitativa, só puderam ser utilizados onze dos treze, devido à falta de respostas na maioria das perguntas.

Os dados adquiridos no questionário e no roteiro estruturado passaram por um tratamento quantitativo e qualitativo, a fim de possibilitar uma melhor visão e entendimento do contexto, como define Malhotra (2001). Os tratamentos escolhidos foram a Análise de Conteúdo proposta por Bardin (2011), composta por técnicas de análise de meio comunicativos com o objetivo de obter indicadores para uma conclusão relativa às condições das mensagens analisadas, e a Análise Descritiva dos dados.

\section{RESULTADOS E DISCUSSÃO}

Conforme os instrumentos aplicados, verificou-se que três empresas incubadas tinham até seis meses de incubação, e as outras dez tem mais de seis meses de existência. A Figura 1 a seguir explora os perfis das empresas incubadas com mais detalhes.

Figura 1 - Perfis das empresas incubadas no ITNC
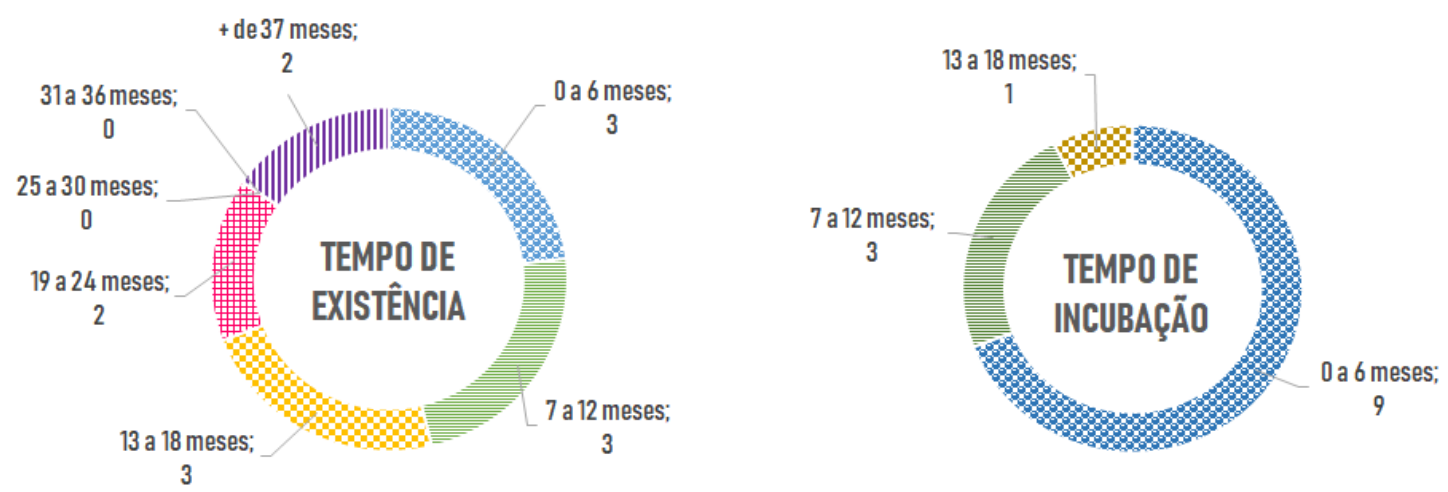

Funcinonários de Carteira Assinada

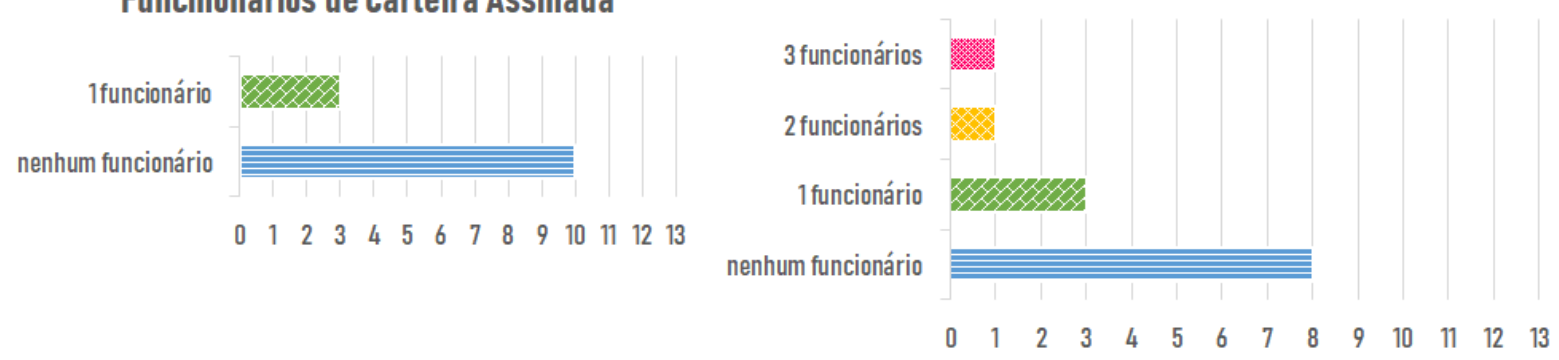

Fonte: Dados da pesquisa 
Como a maioria das startups, as empresas incubadas são micro ou pequenas empresas e a maioria delas é composta apenas por sócios, visto que apenas três empresas tem um funcionário de carteira assinada e cinco trabalham com funcionários terceirizados. Esse número reduzido de funcionários também ocorre com as empresas incubadas em Portugal no Parque de Ciência e Tecnologia da Universidade do Porto - UPTEC, onde metade das 60 empresas que participaram do estudo possui menos de seis trabalhadores (LACERDA, 2012).

A figura 2, página 9, apresenta as idades, os níveis de escolaridade e as áreas de estudos dos empreendedores. Quanto aos empreendedores, doze estão cursando ou já concluíram o ensino superior e a maioria tem entre 23 a 37 anos. Logo, os empreendedores da ITNC já têm um nível de conhecimento teórico elevado e todos eles estudam ou estudaram áreas em que hoje atuam.

A ITNC é uma incubadora cujo foco é inovação tecnológica, então é de se esperar que a maioria dos empreendedores esteja envolvidos em áreas de tecnologia.

Na Figura 2, pode-se observar uma tendência maior para os setores de tecnologias, de engenharia e administração, contudo é possível visualizar que há outras áreas, como medicina veterinária e comunicação. Isso mostra que as empresas incubadas da ITNC não estão focadas somente em setores produtivos tecnológicos. Algumas empresas trabalham diretamente com setores produtivos tradicionais, mas englobam em seus modelos de negócios viés tecnológico, a fim de se diferenciar do mercado. Sua presença na ITNC é um reflexo de que até setores tradicionais então buscando inovar com a ajuda de novas tecnologias.

Figura 2 - Perfil dos empreendedores
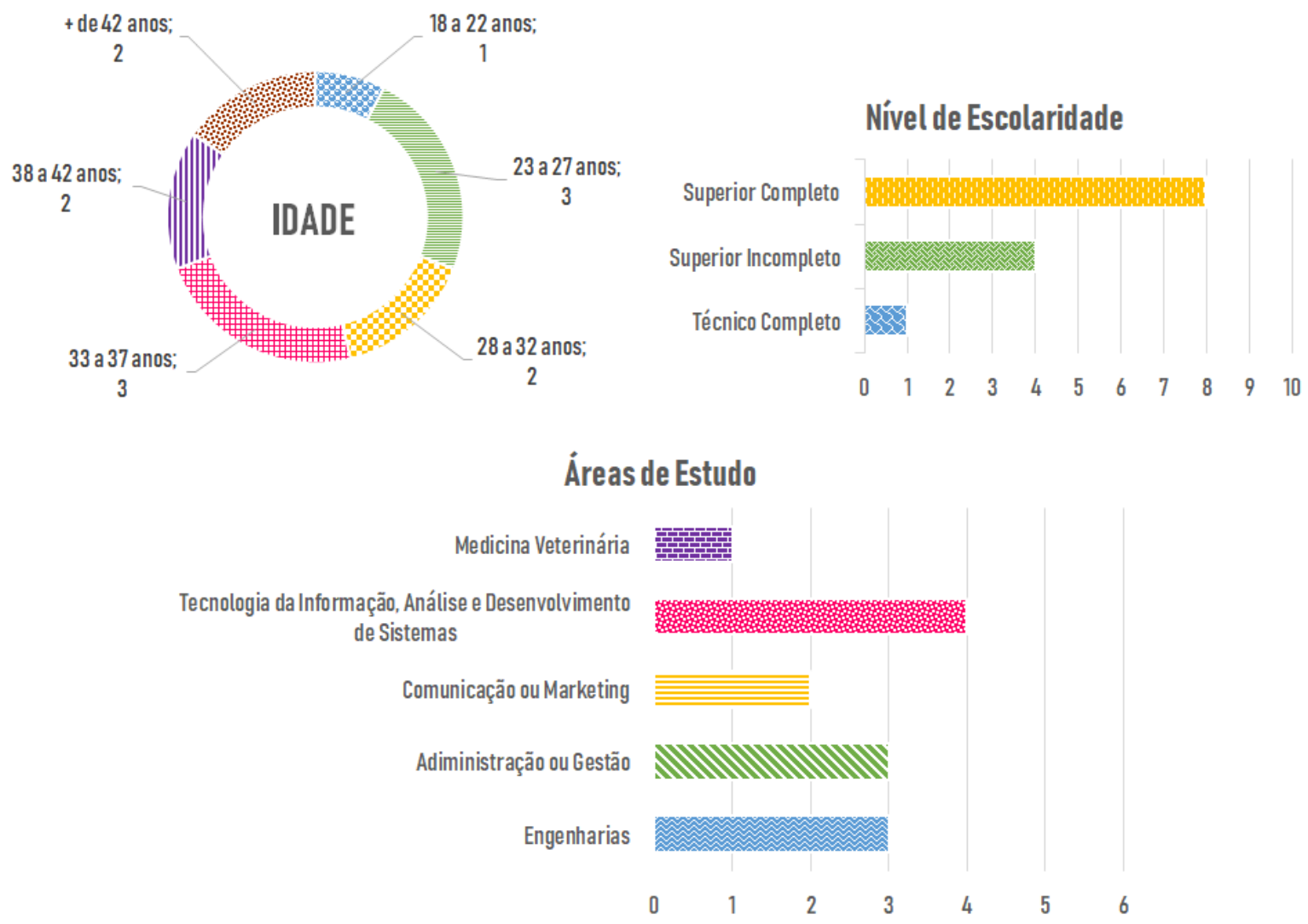

Fonte: Dados da pesquisa 
Quanto aos empreendedores, doze estão cursando ou já concluíram o ensino superior e a maioria tem entre 23 a 37 anos. Logo, os empreendedores da ITNC já têm um nível de conhecimento teórico elevado e todos eles estudam ou estudaram áreas em que hoje atuam.

A ITNC é uma incubadora cujo foco é inovação tecnológica, então é de se esperar que a maioria dos empreendedores esteja envolvidos em áreas de tecnologia.

Na figura 2, pode-se observar uma tendência maior para os setores de tecnologias, de engenharia e administração, contudo é possível visualizar que há outras áreas, como medicina veterinária e comunicação. Isso mostra que as empresas incubadas da ITNC não estão focadas somente em setores produtivos tecnológicos. Algumas empresas trabalham diretamente com setores produtivos tradicionais, mas englobam em seus modelos de negócios viés tecnológico, a fim de se diferenciar do mercado. Sua presença na ITNC é um reflexo de que até setores tradicionais então buscando inovar com a ajuda de novas tecnologias.

Em síntese, observou-se que os empreendedores possuem um bom conhecimento teórico e a maioria está no processo de inserção no mercado ou já se inseriram no mercado.

\subsection{A importância e a satisfação em relação às marcas do instituto e da incubadora}

Os resultados encontrados em relação aos elementos propostos por Lacerda (2012) mostram que a estrutura ofertada, o custo de incubação, os serviços oferecidos pela administração da incubadora, o apoio ao relacionamento com entidades externas, o acesso a rede da instituição e as associações já existentes as marcas ITNC e IFRN são muito importantes para os empreendedores no caminho do seu desenvolvimento. Esses elementos foram avaliados com grau de importância entre 1 a 10, e os resultados podem ser verificados na Tabela 1.

Tabela 1 - Avaliação de Importância

Grau de Importância

Média Mediana

\begin{tabular}{lll}
\hline Estrutura Ofertada & 9,75 & 10 \\
A Marca ITNC & 9,42 & 10 \\
A Marca IFRN & 9,33 & 10 \\
Suporte Técnico no Nível Operacional Ofertado pela Incubadora & 9,25 & 10 \\
Suporte Técnico no Nível Estratégico Ofertado pela Incubadora & 9,25 & 10 \\
Possibilidade de Desenvolver Relações com outras Empresas Incubadas & 9,00 & 10 \\
Apoio da Incubadora na Criação de Relações Externas & 8,83 & 10 \\
Acesso à Rede do IFRN (Núcleos de Pesquisa, Alunos) & 8,50 & 9 \\
Custo da Incubação & 8,08 & 9 \\
Empresas Existentes na ITNC no Momento da sua Decisão de Incubação & 6,67 & 7 \\
\hline
\end{tabular}

Fonte: Dados da pesquisa

Em relação à importância de a incubadora ofertar aspectos (Tabela 1) como motivadores para a escolha da incubação, a estrutura ofertada e as marcas do IFRN e do ITNC 
foram mais significativas. Em Portugal a marca da instituição de ensino mostrou ser o fator mais importante na decisão de ingressar na UPTEC (LACERDA, 2012). Isso mostra a importância da manutenção e da melhoria da estrutura ofertada e de uma boa gestão da marca por parte da incubadora e da instituição de ensino e. O menos significativo foi o aspecto da incubadora já possuir outras empresas incubadas.

Conforme a pesquisa de Teixeira, Tacconi e Tacconi Neto (2020), na percepção das empresas incubadas, o construto legitimidade foi o mais importante para uma empresa se motivar em se inserir em uma incubadora. A legitimidade se refere à capacidade da incubadora de ampliar a reputação e o prestígio da empresa incubada não mercado, especialmente pela rede de cooperação que é gerada com outras instituições, das parcerias estratégicas.

De acordo com Lucion, Endo e Walter (2020), a importância de uma incubadora, que faz com que as empresas tenham interesse em ingressar decorre da possibilidade de reduzir seus custos com a estrutura ofertada pela incubadora, de se capacitar e pela rede de contatos que esse processo oportuniza.

O grau de satisfação das empresas incubadas pode ser visualizado na tabela 2, página 11. O grau de satisfação das empresas incubadas com a ITNC foi alto, sempre com médias entre 8 e 10, com 7 notas máximas de 10 elementos, conforme tabela 2. A marca IFRN foi a mais bem avaliada, seguido da estrutura ofertada e da possibilidade de desenvolver relações com outras empresas incubadas. Essa boa avaliação da marca da instituição de ensino também ocorreu nos resultados do estudo realizado na incubadora portuguesa UPTEC, em que o maior grau de satisfação das empresas incubadas foi com a marca da Universidade do Porto (LACERDA, 2012). O fato interessante é que inicialmente as empresas incubadas costumam se apoiar na marca da instituição de ensino e da incubadora, mas ao longo do tempo tendem a fortalecerem a própria marca.

Na pesquisa de Broze et al. (2019, p. 508) verificou-se que "a marca da incubadora permite abrir portas". As incubadoras têm o potencial de elevar o faturamento e melhorar o atendimento ao cliente das empresas incubadas.

É interessante notar que network interno, relacionado ao elemento "empresas existentes na ITNC" apresentou o valor mais baixo entre as avaliações, que segue na mesma direção da questão anterior sobre os aspectos que são importantes na escolha da incubadora. Isso pode estar relacionado ao tipo de negócio e a experiência dos empreendedores. $\mathrm{O}$ ambiente da ITNC se mostra muito amigável quando se analisa as relações entre os diferentes empresários incubados. Talvez pelo fato de todas essas empresas apresentarem diferentes tipos de negócio, a competitividade interna é quase nula.

Tabela 2 - Avaliação de Satisfação

\begin{tabular}{lcc} 
Grau de Satisfação & Média & Mediana \\
\hline A Marca IFRN & 9,42 & 10 \\
Estrutura Ofertada & 9,33 & 10 \\
Possibilidade de Desenvolver Relações com outras Empresas Incubadas & 9,17 & 10 \\
Suporte Técnico no Nível Operacional Ofertado pela Incubadora & 8,92 & 9 \\
Acesso à Rede do IFRN (Núcleos de Pesquisa, Alunos) & 8,82 & 10 \\
Custo da Incubação & 8,75 & 10
\end{tabular}




\begin{tabular}{lcc} 
A Marca ITNC & 8,75 & 10 \\
Apoio da Incubadora na Criação de Relações Externas & 8,64 & 10 \\
Suporte Técnico no Nível Estratégico Ofertado pela Incubadora & 8,58 & 9 \\
Empresas Existentes na ITNC no Momento da sua Decisão de Incubar & 8,08 & 8 \\
\hline
\end{tabular}

Fonte: Dados da pesquisa

As oportunidades internas são mais aproveitadas pelas empresas de ramos produtivos com produtos físicos. Elas trabalham em parceria entre si e contratam serviços com os incubados com foco no ramo de Tecnologia da Informação (TI). Contudo, as empresas com produtos físicos estão em menor presença na incubadora e por isso a avaliação do elemento "Empresas Existentes na ITNC no Momento da Sua Decisão de Incubar" se configurou como mais baixo. As empresas voltadas a setores de TI avaliaram este elemento com grau mediano devido aos seus modelos de negócio.

\subsection{Valores e associações percebidos em relação ao vínculo com a incubadora e a instituição de ensino}

Para organizar os dados coletados com o roteiro de entrevista e preservar o anonimato das informações, os roteiros receberam códigos EI (Empresas Incubadas) e um número para que se pudesse contabilizar a quantidade de menções dos elementos observados. O Quadro 2 reúne os valores e associações do vínculo das empresas com as marcas ITNC e IFRN.

Quadro 2 - Valores e Associações

Categoria: Valores e Associações

Definição: Que tipo de valores e associações são percebidas em relação ao vínculo com as marcas da incubadora e a instituição de ensino.

\begin{tabular}{|c|l|}
\hline \multicolumn{1}{|c|}{ Temas } & Associações Identificadas \\
\hline \multirow{4}{*}{$\begin{array}{l}\text { Credibilidade - EI01, EI02, EI03, EI04, EI06, EI07, EI10, EI11 } \\
\text { Inovação - EI01, EI10 } \\
\text { Conhecimento - EI01, EI03, EI08 } \\
\text { Networking - EI01, EI03, EI09 } \\
\text { incubados }\end{array}$} & $\begin{array}{l}\text { Aceleração - EI01 } \\
\text { Capacitação - EI03 } \\
\text { Estrutura - EI03, EI08, EI09 } \\
\text { Capacidade técnica - EI04 } \\
\text { Profissionalismo - EI05 } \\
\text { Solidez - EI11 } \\
\text { Comprometimento - EI05 }\end{array}$ \\
\hline
\end{tabular}




\begin{tabular}{|c|l|}
\hline & $\begin{array}{l}\text { Confiabilidade - EI05, EI11 } \\
\text { Equipe gestora capacitada - EI08, EI09 } \\
\text { Apoio - EI08 } \\
\text { Colaboração com outras empresas incubadas - EI08 }\end{array}$ \\
\hline \multirow{5}{*}{$\begin{array}{l}\text { Associações já realizadas } \\
\text { por terceiros }\end{array}$} & $\begin{array}{l}\text { Qualidade - EI11 } \\
\text { Credibilidade - EI01, EI02, EI06, EI10 } \\
\text { Confiança - EI01, EI05, EI06 } \\
\text { Casos de sucesso - EI02 } \\
\text { Rotivação - EI02 } \\
\text { Reconância - EI02, EI05 } \\
\text { Visibilidade - EI03 } \\
\text { Desenvolvimento mais acelerado - EI04 } \\
\text { Seriedade - EI05 } \\
\text { Confiança com instituições financeiras - EI06 }\end{array}$ \\
\hline
\end{tabular}

Fonte: Dados da Pesquisa

Para os empreendedores, estarem vinculados também significa capacitação, profissionalismo, solidez, comprometimento e apoio da equipe gestora capacitada. Esses elementos remetem a uma maior possibilidade de sobrevivência no mercado, não só pela credibilidade bem destacada como também pelo suporte ao empreendedor e sua empresa.

Nas associações realizadas por terceiros (mercado e clientes) é possível identificar que os empreendedores já experienciaram associações relacionadas principalmente a credibilidade, a confiança e o reconhecimento. A confiança também emergiu de forma relevante na pesquisa realizada na UPTEC, demostrando que a associação às marcas da instituição de ensino e da incubadora funciona como uma certificação de confiança e qualidade, uma vez que essas startups já foram aceitas por essas instituições (LACERDA, 2012). Todos esses pontos surgem com mais detalhes na análise de significados.

O estudo de Dantas, Furtado Neto e Severo (2019, p. 64) identificou que o apoio das incubadoras contribui para a "inovação, a performance organizacional e o impacto regional, por meio de novos produtos e processos, renda e riquezas, e a geração de empregos".

\subsection{O significado do vínculo às marcas da incubadora e da instituição de ensino para as incubadas e para o mercado}

Os entrevistados também foram questionados sobre como percebem o significado das marcas IFRN e ITNC para as incubadas e para o mercado. Esse também é um ponto importante para os gestores, visto que as instituições devem fazer com que suas marcas sejam sempre fortalecidas, sendo reconhecidas, aprovadas e se mantendo como a preferida dos consumidores. 
O Quadro 3 dispõe de mais detalhes sobre aspectos como formalidade, valorização, novas oportunidades, inovação, tecnologia e aprendizado contínuo.

Quadro 3 - Significado do Vínculo

Categoria: Significado do Vínculo

Definição: Quais os significados das marcas da incubadora e da instituição de ensino para as incubadas e para o mercado (vivenciados pelos empreendedores incubados).

\begin{tabular}{|c|c|}
\hline Temas & Significados Identificados \\
\hline $\begin{array}{c}\text { Significado para os } \\
\text { incubados }\end{array}$ & $\begin{array}{l}\text { Credibilidade - EI10 } \\
\text { Reputação (valor) para o mercado - EI01, EI11 } \\
\text { Reforça o conceito de inovação e tecnologia - EI01 } \\
\text { Reforça a marca do negócio - EI01 } \\
\text { Reforça o aprendizado contínuo - EI01 } \\
\text { Qualidade, força e experiência - EI02 } \\
\text { Equipe gestora de qualidade - EI02 } \\
\text { Incubadora com casos de sucesso - EI02 } \\
\text { Valorização do negócio - EI03 } \\
\text { Base sólida para crescimento - EI04, EI05 } \\
\text { Olhar para novas oportunidades - EI06 } \\
\text { Aceleração - EI07, EI09 } \\
\text { Formalidade - EI09 }\end{array}$ \\
\hline Significado para o mercado & $\begin{array}{l}\text { Referência em educação de qualidade e tradição (IFRN) - EI01 } \\
\text { Empresas com know-how - EI02, EI08 } \\
\text { Pouco conhecida (ITNC) - EI03, EI04, EI05, EI07, EI09, EI11 } \\
\text { Reconhecimento - EI05, EI09 } \\
\text { Atuação passiva - EI09 } \\
\text { Credibilidade - EI10 } \\
\text { Inovação - EI10 }\end{array}$ \\
\hline
\end{tabular}

Fonte: Dados da pesquisa

As empresas incubadas percebem que as marcas nas quais estão associadas apresentam significados muito positivos como reputação no mercado, base sólida para o crescimento organizacional, aceleração, dentre outros significados expostos no Quadro 3. Isso reforça os achados no quesito valores e associações percebidas em relação ao vínculo com a incubadora e a instituição. Contudo, verificou-se que a marca ITNC ainda é pouco conhecida no mercado. Alguns empreendedores relataram que muitas vezes precisam explicar o que é a 
ITNC e como ela está vinculada ao IFRN, buscando expressar confiança. Entre as pesquisadas, seis empresas citaram que a ITNC ainda é pouco conhecida e uma já ouviu do mercado que a marca tem uma "atuação passiva" quanto a sua presença.

Em entrevista, a gerente da incubadora sobre a marca ITNC alegou que a marca precisa ser fortalecida, mas os recursos são escassos e foram realizados poucos investimentos nessa área. Os recursos têm sido direcionados a capacitação dos incubados e em oportunidades para seus negócios, como auxílios na participação em eventos. Entretanto, foram iniciados esforços nas redes sociais para melhorar a visibilidade da marca. A incubadora definiu em sua estratégia a criação e compartilhamento de conteúdo sobre empreendedorismo e inovação nas redes sociais e atividades para arrecadar recursos e investir no alcance do fortalecimento da marca.

No mercado norte-rio-grandense, a incubadora ITNC está diretamente atrelada à tradição e o reconhecimento da qualidade na marca do IFRN. Como se as duas fossem a mesma pessoa jurídica. Dessa forma, essa pesquisa reflete a importância de a incubadora desenvolver estratégias mercadológicas que a destaquem como entidade única, não perdendo a relação positiva de vínculo com a instituição de ensino IFRN.

Para os incubados, a promoção da marca ITNC e IFRN para o seu negócio é uma fonte de valor agregado por ser responsável em moldar um alicerce sólido em que as empresas possam se apoiar.

A pesquisa de Teixeira, Tacconi e Tacconi Neto (2020) analisou que um dos aspectos que estimulam uma empresa de concorrer para ingressar em uma incubadora é a possibilidade de vincular o nome da incubada com a marca da incubadora e com a marca da instituição de ensino vinculada, que finda por aumentar a credibilidade e oportuniza a negociação com grandes empresas, consolidando a sua empresa no mercado. Questão que uma empresa nova no mercado, sozinha, tem dificuldade.

A incubação possui caráter estratégico de sobrevivência para as empresas, porque gera redes de relacionamentos, que facilitam o acesso a fontes de financiamento. Inclusive financiamentos governamentais direcionados para a promoção de produtos inovadores, que estimulam todo o processo de inovação e que vão se refletir em uma maior capacidade competitiva no mercado em que estão se inseridas (LUCION; ENDO; WALTER, 2020).

O Quadro 4 sintetiza as respostas dos empreendedores quando questionados sobre a importância das atividades de branding das duas instituições.

Quadro 4 - Importância das Atividades de Branding da ITNC e do IFRN

Categoria: Importância das atividades de Branding da ITNC e do IFRN

Definição: Qual a importância do Branding das marcas ITNC e IFRN do ponto de vistas das empresas incubadas.

\begin{tabular}{|l|l|}
\hline Temas & Citações e Comentários \\
\hline $\begin{array}{c}\text { Branding como } \\
\text { apoiadores de } \\
\text { startups }\end{array}$ & $\begin{array}{l}\text { Respaldo e reforços as marcas dos incubados - EI01 } \\
\text { Uma percepção positiva das empresas incubadas - EI01, EI03, EI07 } \\
\text { Visibilidade para os incubados - EI03 }\end{array}$ \\
\hline
\end{tabular}




\begin{tabular}{|l|l|}
\hline Alicerce sólido para que as empresas possam se apoiar - EI04, EI11 \\
Aumento do prestígio das empresas, melhorando o negócio e a confiança - \\
EI08 \\
Possibilidade de parceiros estratégicos para as empresas - EI10
\end{tabular}

Fonte: Dados da pesquisa

Os resultados demonstram que as marcas ITNC e IFRN para as empresas incubadas, seu mercado e clientes funcionam como um alicerce sólido para que as empresas possam se apoiar e atribui ao negócio das startups uma percepção positiva das empresas incubadas. Para empresas que estão no processo de inserção no mercado e crescimento, como é o caso das atuais empresas, ter a confiança do mercado é uma oportunidade de crescimento uma vez que, como mencionado pelos próprios empreendedores, o vínculo possibilita novas oportunidades que resultam em uma maior possibilidade de sobrevivência.

Dantas, Furtado Neto e Severo (2019) verificaram que, dentre os principais apoios ofertados, existe incubadora que permite o uso de sua marca nos materiais gráficos das incubadas. Enquanto Bronze et al. (2019) verificou que os gestores das empresas incubadas consideravam que a boa imagem da incubadora tinha o poder de afetar de forma positiva a confiabilidade do empreendimento frente ao mercado no qual atua. Portanto, concluíram que a Incubadora é um dos fatores críticos para o sucesso desses empreendimentos.

\section{CONSIDERAÇÕES FINAIS}

As incubadoras tecnológicas são instituições que promovem o desenvolvimento local e geram a possibilidade de inovações para pequenas empresas. Nesse sentido, como instituições promotoras do processo de aprendizagem, a relação das incubadoras com instituições de ensino é essencial para o bom desenvolvimento de suas atividades.

As startups pesquisadas, como são pequenas, na sua maioria não possuem funcionários e a parte operacional e estratégica é operada pelos sócios. Os proprietários possuem bom nível educacional, com diversidade de faixas etárias e grande parte já tiveram contato com o mercado empresarial antes de tornarem suas empresas incubadas.

A questão da importância se refletiu principalmente na oferta estrutural da incubadora e no uso das marcas do IFRN e do ITNC, que surgiram como fatores significativos para a escolha de incubar no ITNC. Na mesma direção, a estrutura ofertada, a marca do IFRN e a possibilidade de relacionamento com outras incubadas foram os aspectos que apresentam maior nível de satisfação entre as empresas incubadas.

Os valores e associações percebidos pelos incubados em relação ao vínculo com a incubadora e a instituição de ensino foram muito positivos. Com relação aos valores a credibilidade, o conhecimento, o networking e a estrutura foram os principais elementos levantados pelos incubados. Já as associações realizadas por terceiros destacaram-se a credibilidade, a confiança e o reconhecimento.

Para compreender os significados do vínculo as marcas, verificou-se que as incubadas percebem que as marcas nas quais estão associadas atualmente apresentam significados 
positivos tais como reputação no mercado, base sólida para o crescimento organizacional e aceleração. As startups percebem que associar as suas empresas as marcas ITNC e IFRN geram credibilidade, aspecto essencial para empresas que não possuem boa disseminação de suas próprias marcas consigam crescer e sobreviver no mercado.

Conclui-se que o valor percebido das marcas da incubadora e da instituição de ensino, as quais estão vinculadas, é o elemento-chave para um bom desempenho da empresa no mercado. As diversas associações positivas se tornam um alicerce para a efetivação de oportunidades e a elevação da marca da startup no mercado.

Desta forma, é essencial que incubadoras e instituições de ensino gerenciem as percepções e associações relacionadas às suas marcas uma vez que o branding de ambas está diretamente relacionado ao desempenho das empresas por elas abrigadas.

A continuidade de estudos que possam acrescentar melhorias no desempenho das atividades relacionadas ao fortalecimento das marcas das incubadoras e instituições de ensino se tornam cada vez mais significativos na busca de auxiliar empresas a sobreviver no mercado e promover o desenvolvimento e crescimento da economia.

Para futuras pesquisas sugere-se a aplicação dos mesmos instrumentos de pesquisa em diferentes incubadoras do Rio Grande do Norte e em outros estados brasileiros, a fim de verificar como se comporta a força da marca em incubadoras de diferentes regiões brasileiras.

\section{REFERÊNCIAS}

BROZE, Thiago Silva; FACÓ, Renata Tilemann; SILVA, Luan Carlos dos Santos; SOUZA, Joana Siqueira de; CATEN, Carla Schwengber Tem. Fatores que influenciam o desenvolvimento de empresas incubadas: uma pesquisa de perspectiva. Brazilian Jounal of Business, Curitiba, v. 1, n. 2, p. 500-514, abr./jun. 2019.

DANTAS, Deyseane Kélia Tavares; FURTADO NETO, Joaquim de Siqueira; SEVERO, Eliana Andréa. Análise do apoio ofertado pelas incubadoras de empresas: um estudo de casos múltiplos no Rio Grande do Norte. Revista Metropolitana de Governança Corporativa RMGC, v. 4, n. 2, 2019.

ENGEL, Vonia. Institucionalismo econômico e política de incentivo à inovação no contexto das incubadoras tecnológicas no Rio Grande do Sul. 2018. Tese (Doutorado em Desenvolvimento Regional) - Universidade de Santa Cruz do Sul, Santa Cruz do Sul, 2018.

FACHIN, Odilia. Fundamentos da Metodologia. 6 ed. São Paulo: Saraiva, 2017.

GIL, Antônio C. Métodos e técnicas de pesquisa social. São Paulo: Atlas, 1987.

KOTLER, Philip; ARMSTRONG, Gary. Princípios de Marketing. 15. ed. São Paulo, Pearson Education do Brasil, 2015.

KOTLER, Philip; KARTAJAYA, Hermawan; SETIAWAN, Iwan. Marketing 3.0. Rio de Janeiro: Elsevier, 2010.

KOTLER, Philip; KELlER, Kevin L. Administração de Marketing. 14 ed. São Paulo: Pearson Education do Brasil, 2012. 
LACERDA, Joana Leite de Faria Costa. A importância da marca da incubadora e da universidade para o desenvolvimento do negócio das start-ups. 2012. 99f. Dissertação (Mestrado em Marketing) - Faculdade de Economia - Universidade do Porto.

LUCION, Eric Vinicius; ENDO, Gustavo Yuho; WALTER, Silvana Anita. A incubação de empresas como fator estratégico: um estudo multicasos em incubadoras paranaenses. South American Development Society Journal, v. 6, n. 18, p. 55-81, 2020.

MALHOTRA, Naresh K. Pesquisa de marketing: uma orientação aplicada. 3 ed. Porto Alegre: Bookman, 2001.

MCTIC - Ministério da Ciência, Tecnologia, Inovações e Comunicações. Incubadoras de Empresas. Brasília, 2017. Disponível em: http://www.mct.gov.br/upd_blob/0225/225828.pdf. Acesso em: 14 jun.2017.

PEREIRA, Sónia Maria de Souza. Desenvolvimento de estratégias de marketing: as startups de base tecnológica. 2016. 95f. Dissertação (Mestrado em Marketing) - Faculdade de Economia - Universidade do Porto.

RISCHIONI, Giuseppina Adele; NUNES, Josefa Jostania Silva; BATISTA, Laryssa Feliciano; LUCINDO, Vanessa Michele de Barros. Startup: tendência de negócio no Brasil. REFAS - Revista Fatec Zona Sul, São Paulo, SP, v. 7, n. 1, p. 19-36, 2020.

SHIH, T.; AABOEN, L. The network mediation of an incubator: How does it enable or constrain the development of incubator firms' business networks? Industrial Marketing Management, v. 80, p. 126-138, July, 2019.

SILVA, Edna Lúcia; MENEZES, Estera Muszkat. Metodologia da Pesquisa e Elaboração de Dissertação. 3. ed. Florianópolis: Laboratório de Ensino à Distância da UFSC, 2001.

TEIXEIRA, George Wagner de Paula Gadelha. TACCONI, Marli de Fátima Ferraz da Silva; TACCONI NETO, Ernesto Tacconi. Incubadora tecnológica: os construtos que impulsionam o estabelecimento das relações interorganizacionais. Brazilian Journal of Development, v. 6, n.12, p.103265-103287, 2020.

TYBOUT, Alice M.; CALKINS, Tim. Branding. São Paulo: Saraiva, 2018. 